\title{
Francis Alÿs: Encontros e percursos na Cidade do México
}

\author{
Clara Barzaghi de Laurentiis ${ }^{1}$
}

\begin{abstract}
Resumo: Francis Alÿs desenvolveu, desde o começo dos anos 1990, uma relação bastante interessante com o centro histórico da capital mexicana, onde realiza muitas de suas obras. Este artigo revê alguns aspectos do processo de desenvolvimento urbano da cidade, considerando as transformações que moldaram os contextos urbano e cultural encontrados pelo artista quando chegou em território mexicano, em 1986. A partir de um olhar que busca aquilo que escapa das estratificações do espaço institucionalizado, apresento alguns trabalhos de Alÿs que encaram diretamente a imensidão e o caos urbano da capital mexicana. A partir de uma aproximação dos encontros do artista com essa realidade metropolitana, desenvolvo reflexões disparadas pelas respostas poéticas de Alÿs, que habita a cidade à medida que observa e registra as variadas formas encontradas por outrém, e por ele mesmo, de afirmar suas existências.
\end{abstract}

Palavras-chave: Francis Alÿs; arte contemporânea; metrópole.

\section{Francis Alÿs: Wandering and Encountering through Mexico City}

\begin{abstract}
Francis Alÿs developed since the early 1990s, an interesting relationship with Mexico City's historic center, where he performed many of his artpieces. This article reviews some aspects of the city's urban development process, considering some changes that have shaped the urban and cultural contexts found by the artist when he arrived in Mexican territory in 1986. From a point of view that seeks what is able to escape the institutionalized space's stratifications, I present some of Alÿs' works that directly face the immensity and urban chaos of Mexico City. From a close look of Alÿs' encounters with this metropolitan reality, I establish reflections triggered by the poetic responses invented by Alÿs, who create ways of inhabiting the city as it observes and records the multiplicity of forms encountered by other people, and by himself, to affirm their existences.
\end{abstract}

Keywords: Francis Alÿs; Contemporary art; Metropolis

\footnotetext{
${ }^{1}$ Doutoranda em arquitetura e urbanismo pelo programa de pós graduação em Arquitetura, Tecnologia e Cidade da Unicamp. Mestre em Psicologia clínica - Núcleo de Estudos da Subjetividade, PUCSP, sob orientação do Prof. Dr. Peter Pál Pelbart. Sua dissertação, Mapa Teatro: perspectivas bárbaras da violência, propõe olhar, a partir de uma perspectiva micropolítica, para a violência na Colômbia a partir da produção do laboratório de artistas Mapa Teatro.
} 
Um sujeito diluído na cidade, um caminhante que não pretende inserir objetos no contexto urbano, mas sim fábulas. É assim que Francis Alÿs muitas vezes aparece quando nos deparamos com suas obras desenvolvidas no centro da Cidade do México. Frustrado com sua condição de arquiteto, o artista parece mais interessado em explorar os aspectos já existentes da cidade do que propor soluções ou grandes intervenções. Diante de uma metrópole saturada, o objeto artístico dá, na produção de Alÿs, lugar a fábulas, histórias e rumores que se espalham pela cidade.

Francis Alÿs desenvolve grande parte seu trabalho em um raio de atuação que compreende os arredores de seu estúdio, na Plaza de Santa Catarina, no distrito de Cuauthémoc. Nessa região da cidade se encontra o Zócalo, praça central da capital mexicana que serve de palco para muitas das ações do artista e costumava ser o coração de Tenochtitlan, capital do império Asteca. Tenochtitlan foi originalmente pensada para a defesa, correspondendo a uma política voltada à conquista e ao domínio. Era uma cidade com uma malha urbana ortogonal e em seu centro "se localizavam o centro cerimonial, os mercados e os palácios de reis e nobres” (SÁNCHEZ, s/d: 2).

Com a chegada dos espanhóis, a cidade devastada permaneceu como capital, e o novo traçado urbano, de García Bravo, se baseou na antiga cidade asteca. Até princípio do século XVII, o Zócalo havia se transformado em palco para a monumental arquitetura dos conquistadores e os destroços da antiga Tenochtitlan deram lugar à Iglesia Mayor, ao Palacio de Gobierno, ao Cabildo e ao comércio. Durante o século XVIII, a Cidade do México se consolidou como a mais importante capital dos domínios espanhóis e, com o auge econômico, a cidade teve um desenvolvimento urbano e arquitetônico importante, tendo sido construídos palácios e reformados e ampliados templos e conventos, monumentos e praças, jardins e obras públicas (IBIDEM: 4).

A independência, em 1821, confirmou a Cidade do México como centro político e administrativo da República mexicana. Essa data evoca, ainda, o começo da privatização de uma enorme quantidade de terrenos públicos. Além disso, o período é marcado pela influência francesa, refletida em obras como o Paseo de la Reforma, boulevard de $12 \mathrm{~km}$ de extensão que conecta o Castelo de Chapultepec ao Palácio Nacional, no Zócalo. A expansão e modernização da capital mexicana foram intensificadas na segunda metade do século XIX durante o governo de Porfírio Diaz. Nesse período, a maior parte dos investimentos em urbanização e serviços eram concentrados na região central e o Zócalo era sede dos edifícios do Conselho do Tesouro e da Catedral e a elite se estabeleceu em seu entorno imediato, de modo que os pobres viviam em moradias precárias distantes do centro (MATZKIN, 2006).

Com a revolução de 1910, a população da capital atingiu a faixa de meio milhão de habitantes, número que tendeu a crescer no período revolucionário (1910-1917) e, no ano de 1930, a população já somava mais de um milhão e a superfície urbana havia duplicado no primeiro terço do século XX. O ritmo de crescimento aumentou a partir de 1930 e um milhão de habitantes se transformaram em aproximadamente 18 milhões ao longo do século ${ }^{2}$.

\footnotetext{
${ }^{2}$ Esse número leva em consideração a região metropolitana da Cidade do México e não apenas o Distrito
} 
Atualmente, as zonas centrais das cidades mexicanas, dentre elas a capital, são marcadas pela presença de edificações de diferentes momentos da história, como algumas modestas edificações do século XVI, suntuosos palácios dos séculos XVIII e XIX e, ainda, edifícios mais recentes que evidenciam a modernização das cidades ao longo do século XX (ESPINOSA, 2008).

No final da década de 1980, momento no qual Francis Alÿs passa a se dedicar à prática artística, a região central da cidade, anteriormente habitada pela elite, passava por um processo de deterioração. Essa situação pode ser entendida como decorrência de uma política de planejamento urbano que privilegiou a abertura de vias e circuitos periféricos, transformando os padrões de mobilidade da população. Aqueles que moravam no centro passaram a habitar loteamentos afastados e esse deslocamento foi acompanhado pela conformação de zonas comerciais e de serviços estrategicamente localizadas para cobrir as necessidades dessa população, evitando a necessidade de circular pelo centro (IDEM, IBIDEM).

Durante o século XX, mais precisamente até o final dos anos 1980, as políticas de planejamento urbano no país não atuavam diretamente sobre os centros urbanos, privilegiando a possível conformação de subcentros. Vale notar que o centro da Cidade do México perde muito de sua importância quando o presidente Miguel Alemán (19461952), convencido de que a Universidade de um país modernizado deveria se situar em um grande campus com prédios nos moldes estadunidenses, construiu um novo campus universitário no Pedregal de San Ángel, localizado no sul da cidade há cerca de $22 \mathrm{~km}$ do Zócalo (MONSIVÁIS, 2006). De acordo com o arquiteto e urbanista Salvador García Espinosa,

os primeiros Esquemas de Crescimento Urbano que datam de 1960, assim como os Planos de Desenvolvimento Urbano elaborados até meados dos anos 80, não contemplaram ações particulares sobre os centros urbanos, as propostas sobre a estrutura urbana se enfocavam em prever cenários de crescimento e, em ocasiões, projetar a conformação de subcentros urbanos, mas sempre em pleno reconhecimento de uma estrutura monocêntrica (ESPINOSA, 2008: 5).

É apenas no final dos anos 1980 que a região central reaparece nas discussões de planejamento urbano e surge grande interesse em explorar o potencial turístico ${ }^{3}$ da região. Com isso, o centro urbano passa a ser denominado centro histórico. Não se trata apenas de uma questão semântica, mas de uma ênfase no caráter histórico como recurso a ser explorado pelo turismo cultural. Essas políticas resultam, por um lado, no interesse em uma série de programas de requalificação do centro histórico e, por outro, na tentativa de deslocar a centralidade administrativa e comercial para subcentros urbanos.

A invenção dos centros históricos como elementos da estrutura urbana faz com que se

Federal. Essa informação foi consultada em 2014. O número mais recente encontrado é de 2016 e a população já passa dos 20 milhões. Cf. <http://cdn.plataformaurbana.cl/wp- content/uploads/2016/05/demographiaworld-urban-areas.pdf $>$

${ }^{3} \mathrm{O}$ aparecimento desse interesse no México é concomitante com a inscrição dos centros históricos na Lista de Patrimônio Mundial da UNESCO. O centro da Cidade do México passou a fazer parte da lista em 1987. 
passe de um esquema monocêntrico para um esquema policêntrico de cidade. Isso significa um esforço em zonear uma série de subcentros de caráter administrativo, comercial e até metropolitano de forma que o centro passe a ter caráter majoritariamente histórico-patrimonial (IDEM, 2005).

As recorrentes ações de relocação de equipamentos e serviços para outras zonas da cidade, compreender desde instituições educativas e estabelecimentos comerciais, até oficinas administrativas governamentais e terminais de ônibus. Todas com o argumento de serem incompatíveis com a vocação turística dos centros históricos e propiciarem uma diminuição na intensidade de uso das zonas centrais ( IDEM, IBIDEM: 8).

É notável que o crescente interesse na consolidação do antigo centro urbano como centro histórico é praticamente simultâneo à implementação de uma série de políticas neoliberais no país durante o governo de Miguel de la Madrid (1982-1988).

É nesse contexto de transformações econômicas e espaciais que, em 1986, o então arquiteto Francis Alÿs se muda para a Cidade do México, período que é também marcado por uma crescente presença de artistas estrangeiros no país que colaboraram para que, em pouco mais de quatro anos (1987-1992), a cena artística sofresse grandes mudanças (DEBROISE. In: MEDINA; DEBROISE, 2006). Esses artistas rapidamente se articularam aos jovens artistas mexicanos que estavam fartos de formas artísticas consagradas e buscavam novas fórmulas. Esses jovens da nova geração de artistas nacionais já haviam começado "a meter as mãos nos modos de difusão de suas obras, na teorização e, inclusive, na educação, sem pedir permissão a ninguém e sem que se importassem com as 'políticas culturais' do Estado" (IBIDEM: 328).

A curadora da exposição México Inside Out: Themes in Art Since 1990, Andrea Karnes, atribui ao terremoto de 1985 um papel importante nesse momento de revitalização da arte no país.

O terremoto foi seguido por um despertar político no qual a corrupção governamental, a violência rampante na capital do país, uma crescente brecha entre os ricos e os pobres e a realidade da megalópoles na qual a Cidade do México havia se convertido [...] foi mais exposta (KARNES, 2013).

Tratou-se de um período de insatisfações políticas e promessas de modernização para o século vigente, acompanhadas de fracassos econômicos, que possibilitou a produção de uma nova arte. Apesar de não construírem um movimento específico, os artistas do México pós terremoto se articulavam regularmente em diálogos críticos, compartilhavam preocupações formais e conceituais, frequentavam espaços artísticos independentes e, ocasionalmente, exibiam juntos suas obras (IDEM, IBIDEM: 9).

As discussões formais e críticas desses artistas buscavam referências, por um lado, na arte conceitual europeia e estadunidense e, por outro, na produção contracultural mexicana dos anos 1960 e 70 e suas reverberações na arte. O ano de 1968, na Cidade do México, foi marcado por dois eventos antagônicos e por uma situação sociopolítica 
de crise. Por um lado, se tem a realização das olimpíadas no México, para a qual foi desenvolvida uma intervenção artística chamada Ruta de la Amistad. Essa intervenção consistiu na criação de um passeio escultórico que respondia a uma linguagem de internacionalidade e transmitia uma mensagem de paz, irmanada com a ideologia olímpica (ORTEGA, 2012).

Por outro lado, o ano foi marcado por uma série de manifestações de estudantes na capital mexicana, que questionavam a autoridade do Estado e os valores tradicionais ${ }^{4}$. Uma dessas manifestações, ocorrida no dia 02 de outubro, deixou mais de 150 mortos e marcou o início de uma rigorosa repressão política e cultural nas ruas da cidade do México ${ }^{5}$. Com isso, o medo da repressão resultou no esvaziamento das ruas e a cultura juvenil se viu censurada, passando a operar "de modo mais ou menos subterrâneo até meados dos anos 1980" (MEDINA, 2006: 6).

Como uma forma de desdobramento das manifestações de 1968, muitos dos jovens manifestantes se juntaram para formar os Grupos, coletivos artísticos que, explorando diversos materiais e técnicas, buscavam retomar o espaço urbano, bem como as discussões políticas. Muitos destes Grupos tinham um trabalho essencialmente político e se aproximavam da arte conceitual. O que pretendiam não era uma arte conceitual latino-americana, "mas uma arte política inscrita na história latino-americana" (TOURNON, 2012/2013: 39).

A redefinição do conceitualismo mexicano em termos de Grupo correspondeu, portanto, a um processo de politização de seus protagonistas que [...] escolheram uma política: uma maneira de fazer arte que implica e produz um tipo de espaço onde a oposição teria seu lugar (IDEM, IBIDEM: 40).

Os Grupos se consolidam como movimento artístico após a "X bienal de jovens em Paris" (1977), quando Helen Escobedo, diretora do Museo Universitario de Ciencias y Artes (MUCA), ficou encarregada de selecionar os representantes mexicanos da mostra e, no lugar de artistas que trabalhavam individualmente, optou por convocar alguns dos Grupos recém formados: Suma, Proceso Pentágono e Tetraedro. Após o evento, logo apareceram novos coletivos. Muitos dos Grupos formados antes e depois da "X Bienal" estavam comprometidos com uma temática política. Alguns trabalhavam com estratégias informativas, como por exemplo o grupo Germinal, pintando mantas que se transformavam em murais ambulantes nas manifestações. Outros dos Grupos, como Proceso Pentágono e Suma, discutiam política de uma maneira pouco panfletária. O primeiro abordava temas como a tortura na américa latina e a realidade política e econômica do México. Suma, por sua vez, trabalhava a partir das tensões políticas e econômicas que se refletiam pelas ruas da cidade (MANTECÓN. In: MEDINA; DEBROISE. 2006).

No entanto, não se pode dizer que a questão política era comum a todos os Grupos. Alguns se mostravam mais interessados em questionar linguagens e materiais, explorando suportes como fotografia, cinema e áudio. De todo modo, os Grupos

\footnotetext{
${ }^{4}$ Francis Alÿs retoma os eventos de 1968 na obra Contos Patrióticos

${ }^{5}$ Cf. La masacre de Tlatelolco, 2008, Matias Gueilburt.
} 
começaram a desaparecer no começo dos anos 1980, apesar de sua vitalidade. Isso se deu, em parte, devido à diminuição da militância política, em função da incorporação dos partidos políticos de esquerda à vida institucional ${ }^{6}$; mas também devido ao esgotamento de seu repertório. Alguns dos artistas desses coletivos, como Gabriel Orozco, voltaram ao trabalho individual e, posteriormente, se engajaram nas transformações da arte no começo da década de 1990.

Além de Orozco, a nova geração de artistas contava com Eduardo Abaroa, Abraham Cruzvillegas, Daniel Gusmán, que se somavam aos estrangeiros Melanie Smith, Thomas Glassford e Francis Alÿs, entre outros. Muitos desses artistas, assim como Alÿs, optaram por morar no centro histórico da Cidade do México, recém recuperado como foco de intervenções urbanas que, posteriormente, levariam à gentrificação da região central.

Em Abril de 1989, quando [Silvia] Gruner e Pérez Monzón se mudaram para o apartamento desocupado pelo poeta Armando Sariñana, na rua Licenciado Verdad, logo abaixo do estúdio do texano Michael Tracy, Melanie Smith ocupou a Plaza Santa Catarina, onde a alcançou Francis Alÿs, recém 'convertido' à arte (DEBROISE. In: DEBROISE; MEDINA, 2006, p.330).

Se, por um lado, os artistas desse novo período de efervescência problematizaram questões particulares do país, por outro, suas produções fizeram com que o México passasse a ser mundialmente reconhecido pelo mercado da arte. Dessa forma, a produção desses artistas, dentre eles Francis Alÿs, deve ser pensada em suas especificidades, sem que sejam ignorados o processo de globalização da arte contemporânea e o fervor que acometeu o âmbito das artes ao longo da década de 1990.

Os ventos que agitaram o território da arte no México não constituíam um caso isolado. A produção artística em todo o mundo reaparece com força nos anos 1990, tendo suas principais origens no mal estar da política que rege os processos de subjetivação no capitalismo financeiro que se instaurou mundialmente a partir de 1970 (ROLNIK, 2006). De acordo com a psicanalista, curadora e crítica cultural Suely Rolnik

o capitalismo cognitivo ou cultural, concebido justamente como saída para a crise provocada pelos movimentos dos anos 1960/70, incorporou os modos de existência que estes inventaram e apropriou-se das forças subjetivas, em especial da potência de criação que então se emancipava na vida social, a colocando de fato no poder, tal como haviam reivindicado aqueles movimentos (IDEM, IBIDEM: 6)

O capitalismo cultural que se instaura no final dos anos 1970 como alternativa aos reflexos causados pelos movimentos das duas décadas anteriores incorpora as experimentações transgressivas das décadas que o precederam e seus protagonistas que,

\footnotetext{
${ }^{6}$ Em 1977, foi decretada a Ley de Organizaciones Politicas y Procedimientos Electorales (LOPPE), que permitia que os partidos de esquerda, proscritos à época, se regularizassem. A incorporação à vida institucional levou a uma desmobilização da militância vinculada aos Grupos. MANTECÓN, Álvaro Vázquez. Op. cit.
} 
interpretando esse movimento como sinal de reconhecimento, se entregaram à cafetinagem ${ }^{7}$, tornando-se os próprios concretizadores da nova faceta do capitalismo.

As práticas artísticas, no entanto, não permanecem indiferentes a esse movimento e o começo dos anos 1990 é marcado por uma tomada de consciência e pela problematização da situação que se instaurou.

\section{Olhando para a cidade}

Francis Alÿs, que se mudou para o México para trabalhar em organizações não governamentais que atuavam nas áreas atingidas pelo terremoto de 1985, se deparou com uma cidade marcada pelo avanço do Capitalismo Cultural e das políticas neoliberais, acompanhados por um crescente interesse em revitalizar o recém nomeado Centro Histórico.

No final dos anos 1980, Alÿs estava prestes a finalizar seu contrato com as organizações não-governamentais e retornaria à Bélgica, mas enfrentou uma série de problemas legais por ter se ausentado do serviço militar. Simultaneamente, Alÿs encontra pelas ruas do centro da cidade as novas experimentações artísticas que começavam a pipocar pela capital.

Em 1989, a ponto de finalizar seu contrato, deambulando pela Cidade do México na rua de Cuba, viu um tumulto em frente a uma loja de móveis transformada em galeria de arte, que se chamava El Salón des Aztecas ${ }^{8}$. Nessa noite quente de Março era inaugurada uma exposição de um contingente de artistas britânicos que, em uma reunião em um pub de Londres, meses antes, haviam decidido emigrar ao México em busca de uma alternativa a um mundo de arte, então dominado pela pintura, que oferecia poucas possibilidades aos artistas jovens (DEBROISE. In: MEDINA; DEBROISE, 2006, p.329).

Nesse mesmo ano, Alÿs passou a se dedicar à prática artística nessa - e a partir dessa cidade, marcada, simultaneamente, pela presença de um projeto de modernização característico do neoliberalismo, pela permanência de aspectos, arquitetônicos e culturais, do México pré-colonial e colonial e pelas movimentações intensas que

\footnotetext{
7 O termo cafetinagem empregado pela autora se refere à relação estabelecida entre capital e cultura no neoliberalismo. Não é absolutamente casual que o termo remeta à obvia relação entre prostituta e cafetão. Para Rolnik, a escolha de palavras parece pertinente, pois ambas as relações incidem sobre o erotismo e a semelhança se estende ao modo como operam: o abuso perverso. Muda apenas a dimensão do erotismo que cada uma dessas relações privilegia: se no primeiro caso, seu objeto é o erotismo vinculado à sexualidade strictu sensu (embora envolva a existência da prostituta como um todo), já no segundo, seu objeto é o erotismo no sentido amplo da vida enquanto potência de germinação de mundos - ou seja, a vida em sua essência.
}

${ }^{8}$ O Salón des Aztecas foi inaugurado por Aldo Flores, em 1988, como um primeiro espaço artístico independente que ajudaria a transformar o centro da Cidade do México numa espécie de Soho latinoamericano. Flores acreditava que os artistas tinham potencial para trasnformar o espaço urbano e teve o tino de abrir as portas a muitos dos artistas estrangeiros que se mudaram para a cidade no fim dos anos 1980 e que participaram intensivamente na produção de arte da década seguinte. Cf. http://www.mexartdb.com/\#/proyectos/salon-desaztecas e MEDINA; DEBROISE, 2006) 
começavam a agitar o território da arte. A partir daí, o artista passa a experimentar uma poética visual, na qual a própria cidade - em especial o centro - se torna matéria de investigação. Para Alÿs

México é uma cidade que te obriga constantemente a responder a sua realidade, te obriga a todo tempo relocalizar sua presença, a reposicionarse diante desta entidade urbana desmesurada. É exatamente o que posso observar todos os dias em minhas direções, com toda essa gente que não deixa de se reinventar: gente que um dia sente a necessidade de construir uma personalidade, uma identidade para afirmar seu sítio neste caos urbano (ALŸS; DIESERENS, 2006: 121).

As respostas de Alÿs a essa situação urbana partem das ações, quase contemplativas, de caminhar, observar e registrar a vida como ela é no centro de uma das maiores cidades do mundo. A imensidão da cidade foi, simultaneamente, uma dificuldade enfrentada pelo artista e o disparador de seu processo investigativo. Sem conseguir compreender como a sociedade funcionava como um todo, Alÿs passou por um primeiro momento de observação, tentando perceber de que maneira as pessoas reagiam ao caos urbano.

Eu vivia no antigo Centro Histórico, onde havia todos esses personagens, pela falta de uma palavra melhor. Eu vi como eles sentiam a necessidade de criar uma identidade, de inventar um papel para si mesmos, um ritual que justificaria sua presença no tabuleiro urbano - como esse cara, com seus quarenta e poucos anos, que eu via toda manhã andando de cima para baixo no Zócalo com um fio metálico dobrado em forma de gancho com um círculo no final, uma espécie de roda de bicicleta sem os raios. Começando do canto superior esquerdo da praça, ele seguiria todas as pequenas fendas entre as pedras da pavimentação, metodicamente andando (pacing) pela praça toda. Era o papel que ele inventou para si mesmo. Era sua forma de estar lá, de ser parte da vida da cidade. Encontrar essas pessoas foi, frequentemente, o ponto de partida (entry point) para minhas caminhadas ou intervenções, o cru e poético ponto de partida (ALŸS; FERGUSON. In: MEDINA; FERGUSON; FISHER, 2007: 8).

Em um primeiro momento, portanto, a relação de Alÿs com a cidade era pautada pela observação, em sua tentativa de compreender a dinâmica urbana e a forma como as pessoas se inseriam nesse ambiente. Essa incessante observação o leva a se questionar o quanto pertencia àquela cidade e poderia julgá-la ou participar de sua dinâmica. Em 1994, há quase uma década vivendo ali, esses questionamentos ganham forma na obra Turista, registro fotográfico de uma ação na qual Alÿs denuncia e testa seu status de estrangeiro, de gringo. 


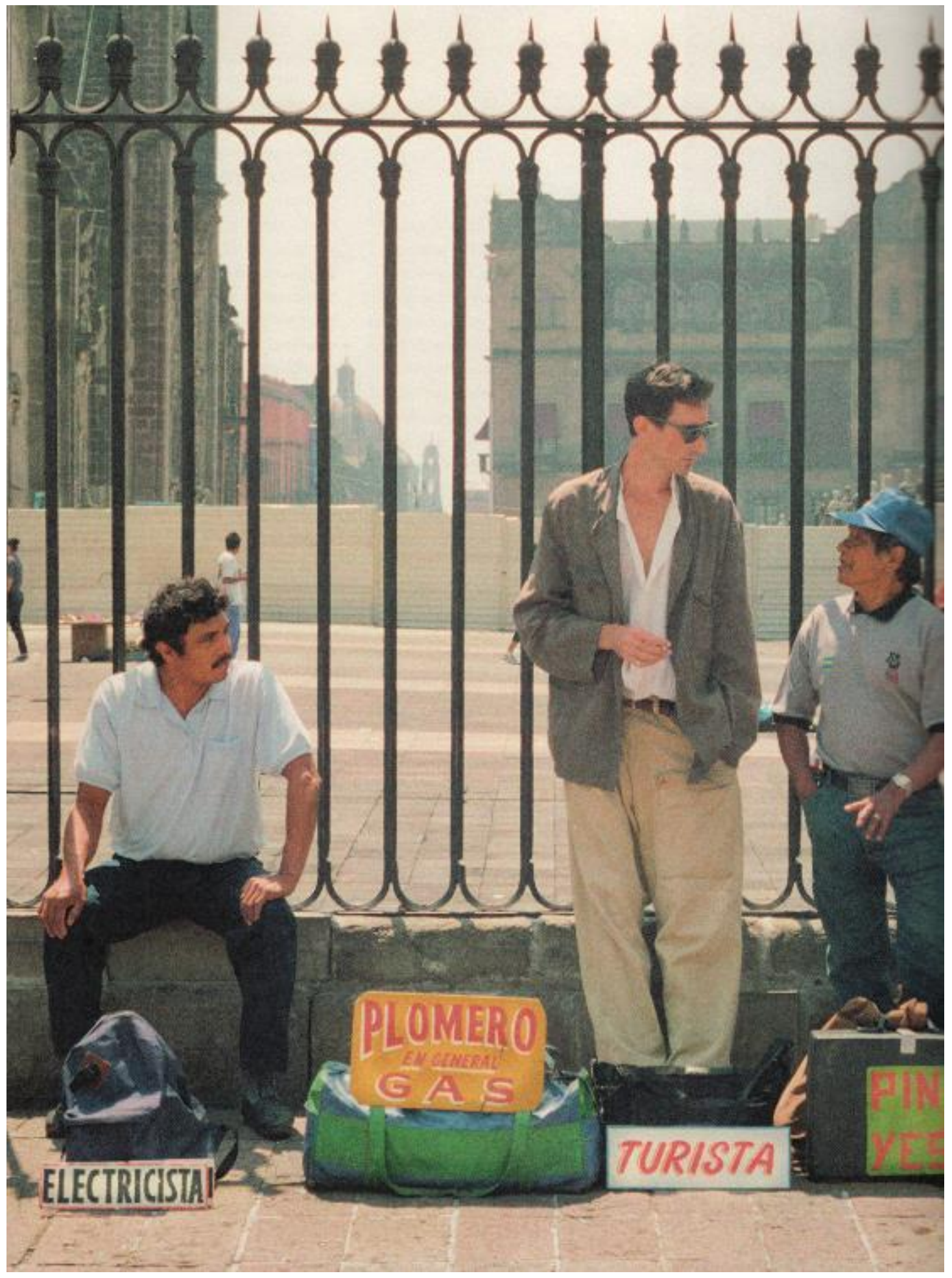

Francis Alÿs, Turista, 1994, registro fotográfico de uma ação, catedral metropolitana, cidade do México. 
As fotografias registram uma situação cotidiana: do lado de fora das grades da Catedral Metropolitana, no Zócalo, diversos trabalhadores informais oferecem seus diferentes serviços. No entanto, entre carpinteiros, encanadores, pintores, pedreiros e eletricistas, está Alÿs com seus óculos de sol e sua aparência tipicamente europeia oferecendo seus serviços como turista. Com essa obra, o artista se reconhece como outsider sem se excluir da vida na Cidade do México, se coloca num ponto intermediário entre "prazer e trabalho, contemplação e interferência" (IDEM, IBIDEM: 11).

Essa combinação entre observação e interferência acompanhou a obra do artista ao longo da década de 1990, especialmente a partir da segunda metade, e persiste ainda hoje. Se, por um lado, Alÿs registra diversas expressões do uso do espaço urbano, por outro, compreendeu que, ao viver em uma cidade e atuar nela, não seria possível se manter em uma situação completamente passiva. Ações interferem no espaço, bem como o espaço produz reflexos no corpo e nas sensações.

O artista entendeu que não poderia ser apenas observador das obras em 1996, quando filmou Si eres un espectador típico, lo que realmente haces es esperar a que suceda el accidente, vídeo no qual segue com a câmera uma garrafa de plástico que era arrastada pelo vento no Zócalo. Ainda que pretendesse ser passivo, apenas esperando o acidente, em pouco tempo os transeuntes, encorajados pela câmera, começaram a chutar a garrafa. $\mathrm{O}$ mero ato de filmar altera as variáveis da cena. $\mathrm{O}$ acidente que Alÿs esperava aconteceu de maneira diversa; entretido pela movimentação da garrafa, o artista distraído foi atingido por um automóvel. Para Alÿs, esse vídeo marca simbolicamente a impossibilidade de distanciar-se enquanto artista da sociedade ao seu redor. Chegou, assim, o fim do período de sua obra marcado pela não interferência.

Voltando a Turista, um outro aspecto merece ser notado: a situação escolhida para realizar sua ação. $\mathrm{O}$ artista opta por registrar uma expressão do comércio informal, a partir de um ponto de vista que não exclui essas pessoas do contexto urbano; pelo contrário, resgata suas práticas como pertencentes da dinâmica do centro da cidade. Essa opção por registrar o uso informal da rua não é totalmente casual e vem se repetindo ao longo do trabalho de Alÿs em séries fotográficas a partir das quais o artista investiga a cidade.

Em suas séries de fotografias, Alÿs retrata figuras características da vida no centro da cidade. Em dormientes, registra o uso da rua por pessoas e cachorros que dormem nas calçadas do centro da capital mexicana. As primeiras fotos das série foram tiradas no ano de 1999 e o artista continua os registros ainda hoje, com a intenção de "resgatar práticas e formas de formas de vida que podem chegar a desaparecer a qualquer momento devido a um ato administrativo ou de regulamentação" (ALŸS; MEDINA, 2006, p. 73). 


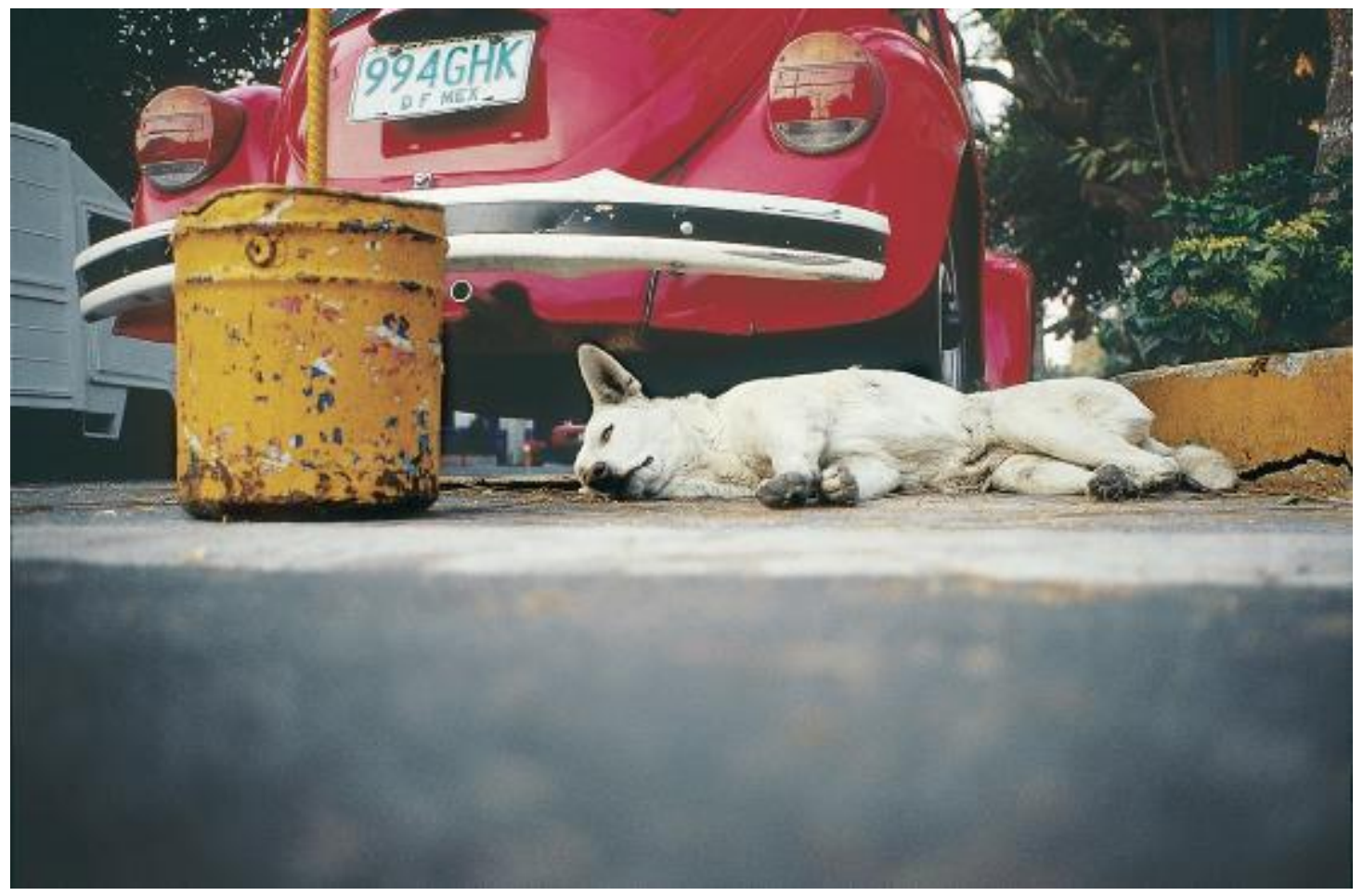

Francis Alÿs, Dormientes, (1999- 2006), fotografia, cidade do méxico.

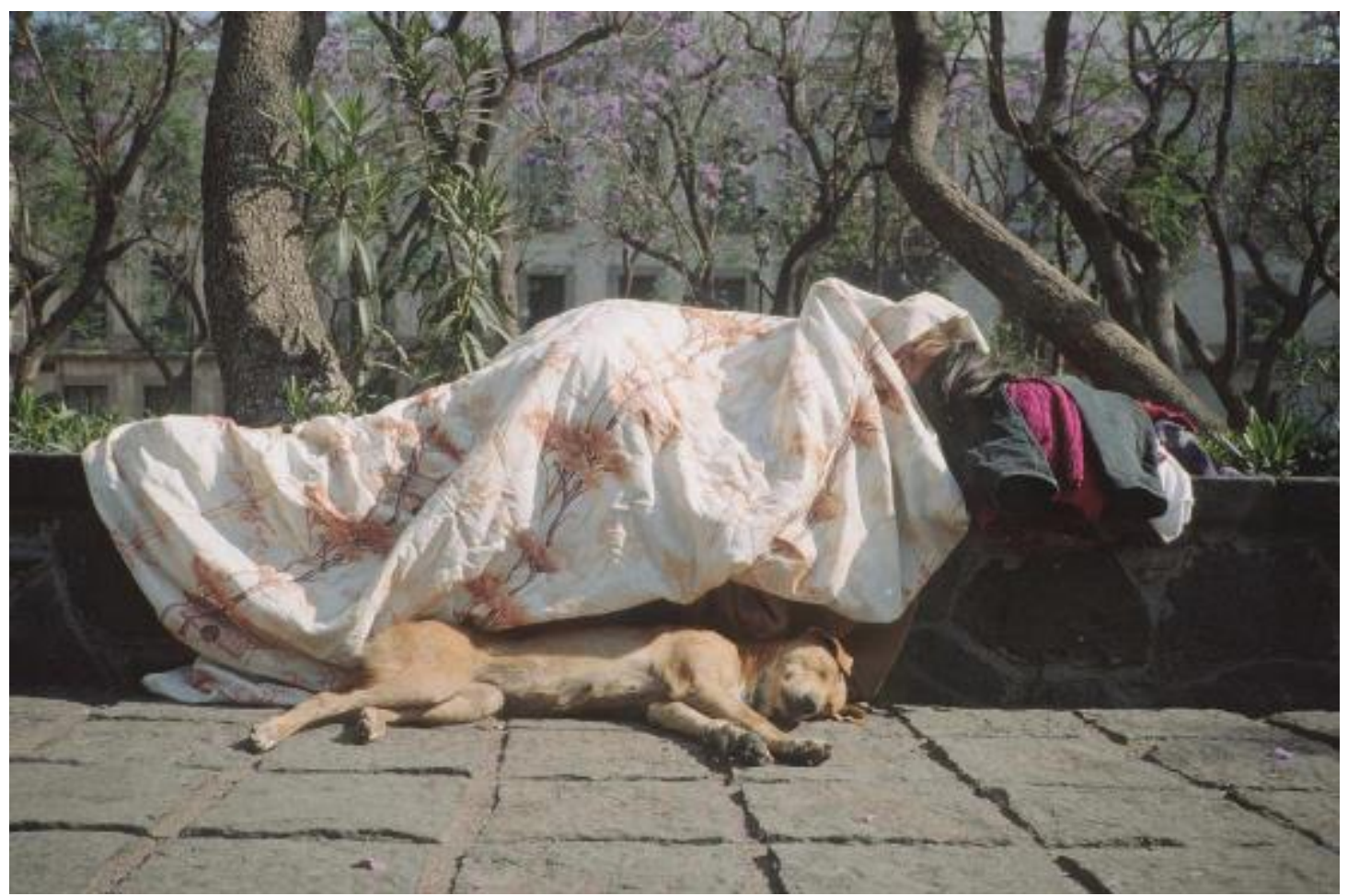

Francis Alÿs, Dormientes, (1999- 2006), fotografia, cidade do méxico. 
Essas fotos são sempre tiradas a partir do nível do solo, num plano horizontal, garantindo um registro no mesmo nível onde se encontra o dormente, evitando um ponto de vista hierárquico por parte do observador. A série pode ser pensada como uma tentativa de expor algumas formas privadas de apropriação da rua, que normalmente seria destinada a uma função pública de tráfego (IDEM, IBIDEM). Em dormientes, além de pessoas, vemos cachorros que dormem na rua. Alÿs demonstra um interesse grande pelos cães que vivem na rua da Cidade do México, inclusive já lhe foi dito que o fator humanizante da série fotográfica é a presença desses parasitas urbanos que são os cães (AL ŸS; DISERENS, 2006, p. 104). Para o artista, esses animais conseguem transmitir a sensação de liberdade que pode encontrar vivendo no México,

se bem que falar de liberdade nesse caso é um pouco abstrato, para não dizer politicamente incorreto. Poderíamos encontrar toda uma série de elementos que se opõem a essa noção de liberdade estritamente política, econômica ou racial. Mas, ao mesmo tempo, aqui encontrei um sentimento de ilusão de liberdade que não havia conhecido em nenhum outro lugar (IDEM, IBIDEM: 107).

A existência de uma fauna urbana tem sido interesse de Alÿs desde seus tempos de arquiteto em Veneza, antes de se mudar para a Cidade do México. Em sua tese de doutoramento, desenvolvida no IUAV de Veneza, o artista buscou estabelecer um paralelo entre o desparecimento dos animais - inclusive por medidas de saúde pública - das cidades pré-renascentistas e a desaparição crescente do conceito de animalidade das representações populares da época, como, por exemplo, na produção dos iluminadores.

A crescente preocupação com a saúde da população, no final do século XVI e começo do século XVII, levou a um processo de especialização da arquitetura, desde o final o século XVIII, pautado pelos problemas da população, da saúde e da circulação no espaço urbano (FOUCAULT, 2009).

De acordo com o arquiteto Andrea Cavalletti, a partir do século XVIII, portanto, a população se torna um princípio econômico e político fundamental, "uma máquina que pode ser governada através da gestão das condições de vida (habitat, cidade, higiene, segurança no sentido mais amplo do termo)[...]" (CAVALLETTI, 2010, p.17). A população se torna o fim último do governo e, com isso, o planejamento urbano passa a ser orientado para garantir a saúde pública, a partir da abertura de grandes vias na cidade (CAVALLETTI, 2010; SENNETT, 2003).

Vale notar que os urbanistas modernos buscaram nos iluministas as noções de veias e artérias no espaço urbano, pautadas pela preocupação com a saúde pública e a respiração nos centros de cidades. No entanto, eles utilizaram esse imaginário para permitir novos usos, voltando-se para a livre circulação e a velocidade. A pretensão de facilitar a circulação das multidões somada à tentativa de desencorajar manifestações de grupos organizados, fez com que os corpos que circulavam pelas cidades planejadas do século XIX passassem cada vez mais desapercebidos uns pelos outros e pelos espaços. A maior expressão disso foi a Paris de Haussmann, que influenciou, na 
segunda metade do século XIX, muitas cidades da América Latina, dentre elas a Cidade do México.

A cidade da modernidade apresentava dois aspectos arquitetônicos e urbanísticos que a norteariam: por um lado, a liberação dos espaços para circulação garante uma cidade que respira livre de endemias. Por outro, a cidade é marcada pelo crescente confinamento dos delinquentes. De acordo com Foucault, o personagem do delinquente é delineado no final do século XIX e sua existência é concomitante à importância que se passa a dar ao confinamento.

A constituição do meio do delinquente é absolutamente correlativa à existência da prisão. Procurou-se constituir, no próprio interior das massas populares, um pequeno núcleo de pessoas que seriam, por assim dizer, os titulares privilegiados e exclusivos dos comportamentos ilegais. Pessoas rejeitadas, desprezadas e temidas por todo mundo (FOUCAULT, 2006, p.47).

Ora, se na cidade moderna o planejamento urbano é norteado pelas demandas de saúde pública e pela tentativa de normalização dos delinquentes, talvez seja possível pensar que, na cidade contemporânea, essas políticas urbanas se atualizam e são expressas nos crescentes projetos de gentrificação dos centros urbanos.

De acordo com Alÿs, a capital mexicana apresenta uma espécie de resistência aos processos de modernização; especialmente no que diz respeito ao centro histórico, marcado por anacronismos e características pré-Hispânicas, coloniais e modernas. Em entrevista com Corinne Diserens, o artista afirma que o movimento, característica primeira da modernidade, tem sua maior expressão no Zócalo, no entanto,

pode resultar bastante paradoxal o fato de que sua manifestação mais evidente seja aqui, no centro histórico, em uma zona que funciona precisamente de maneira anacrônica e mais ou menos à margem das regras habituais da cidade moderna; seja em sua organização social, sua economia, sua jurisdição etc (ALŸS; DISERENS, 2006, p. 107).

Pode-se pensar que a cidade flerta com a modernidade sem, no entanto, se entregar completamente a ela. No entanto, ainda que o centro cidade não tenha passado por um processo de modernização nos moldes ocidentais ${ }^{9}$, a retomada de interesse pela região nos projetos urbanos é característica das cidades contemporâneas marcadas pela presença do neoliberalismo e do capitalismo cultural. Talvez por essa razão, o registro sistemático que Alÿs realiza de determinados usos do meio urbano e o valor que dá à fauna urbana são encarados por Medina como "exemplo de resistência à crescente obsessão de controle cívico" (ALŸS; MEDINA, 2006, p.73). Seguindo essa lógica, os cachorros de rua podem ser pensados como um fenômeno do espaço urbano que

\footnotetext{
${ }^{9}$ Vale lembrar que o centro ficou esquecido pelas políticas de planejamento urbano até a segunda metade do século XX, mas que uma série de reformas urbanas foram feitas no território mexicano no sentido de modernizar a cidade, privilegiando a circulação e a velocidade, seguindo um padrão que marcou a Europa moderna.
} 
evidencia, simultaneamente, a deterioração e as tentativas de requalificação da região central da cidade.

Se a rua é como o grande hotel dos párias, as calçadas são o espaço de salvação dos cães, que estão ali porque o Centro (a entidade que é algo mais do que a soma de seus habitantes, proprietários e viajantes) não admite ver- se regimentado pelo culto ao Progresso ou à Pós-modernidade e se agarra seu aspecto irredimível. (MONSIVÁIS, 2006, p.89)

Ao longo dos últimos anos, o centro histórico da Cidade do México tem passado por um processo de gentrificação, semelhante aos processos vividos por cidades como Nova York, São Francisco, Chicago, etc. Francis, apesar de não se colocar contrário a esse processo, opta por privilegiar as imagens da deterioração, não com a intenção de explorar uma "estética da pobreza", mas sim as possíveis apresentações de um "estado de coisas", "uma reelaboração do Centro da cidade de energias sempre inesperadas e, mais especificamente, um retrato da jornada artística que combina urbanismo, sociologia e experiência de residente" (MONSIVÁIS, 2006, p.89).

Além dos dormientes, o artista vem registrando, desde o começo dos anos 1990, a presença dos ambulantes nas ruas do centro da cidade. Nessa série Alÿs dirige o olhar a uma variedade de carrinhos, suportes e objetos que são empurrados, puxados ou carregados pelas ruas. $\mathrm{O}$ artista registra os participantes de uma economia informal, que usam o espaço público de forma que "incorporam a recusa de populações urbanas em se conformar aos padrões tecnológicos, sociais e culturais do ocidente moderno" (ALŸS; MEDINA. In: GODFREY, 2010, p.56). 


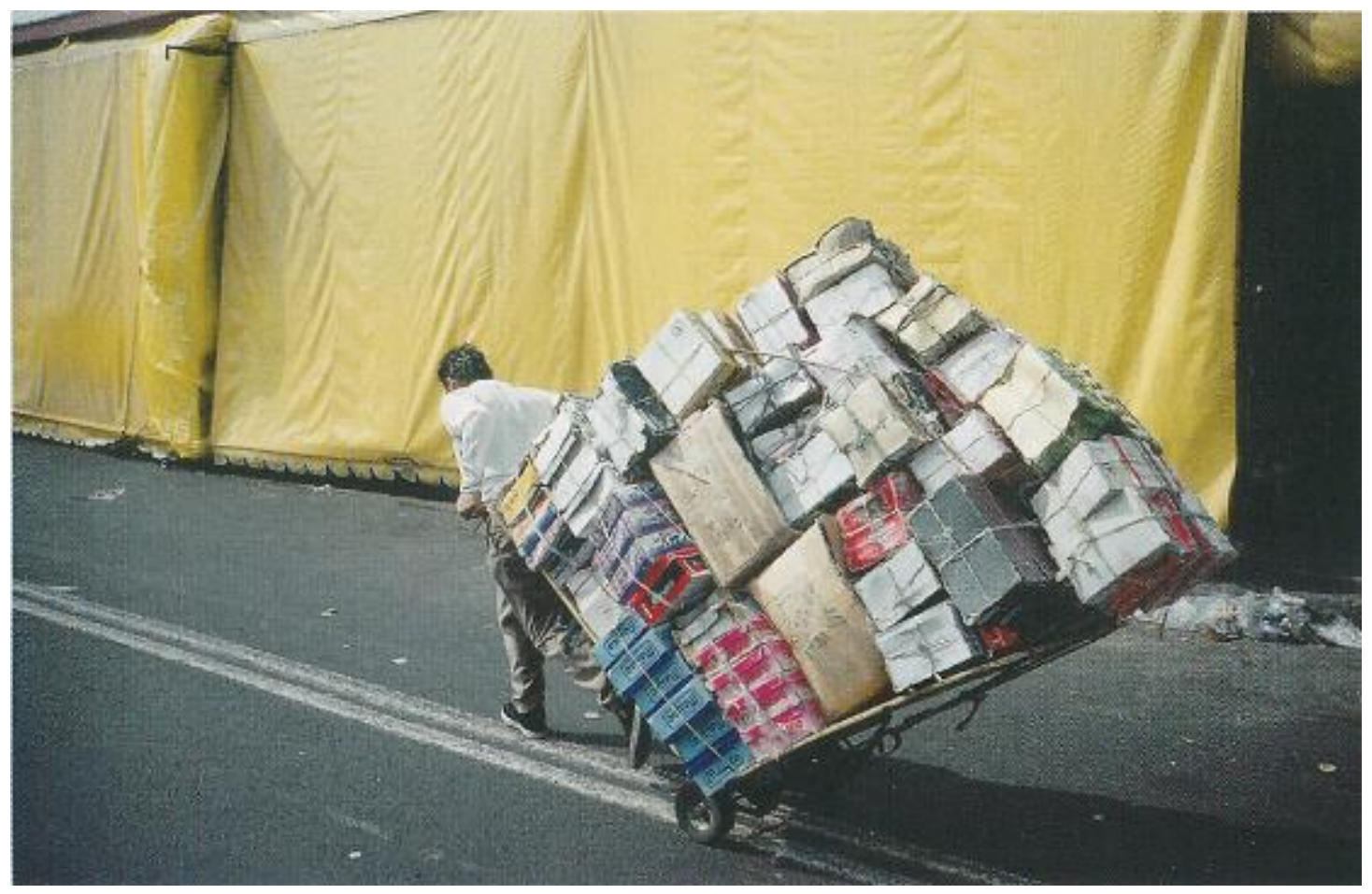

Francis Alÿs, Ambulantes, (1992- 2006), fotografia, cidade do méxico.

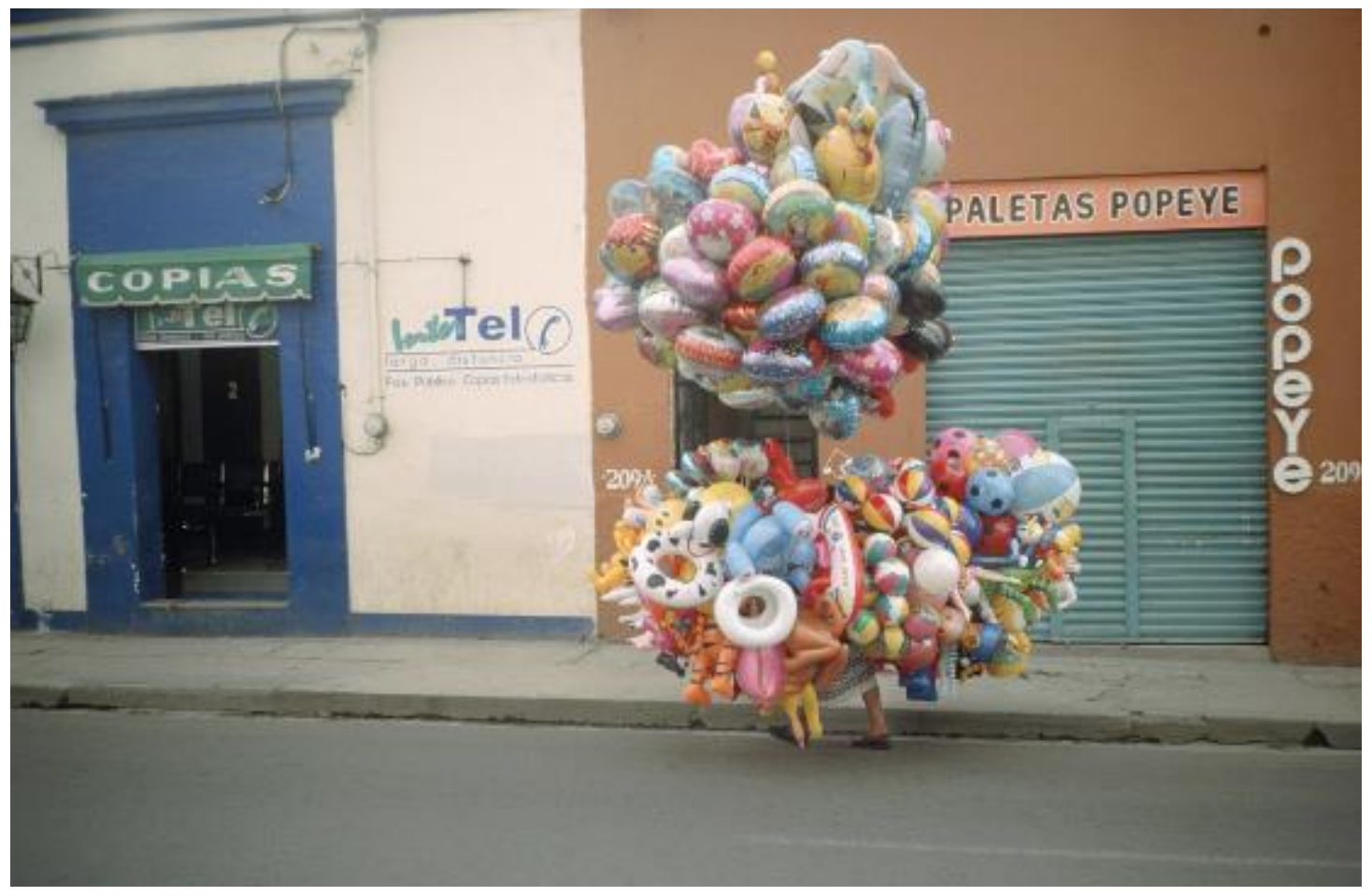

Francis Alÿs, Ambulantes, (1992- 2006), fotografia, cidade do méxico. 
Para Alÿs, a série é uma forma de registrar os improvisos e táticas de sobrevivência no contexto urbano. O registro da presença de vendedores ambulantes no centro da capital mexicana como forma de resgate de práticas cotidianas que tendem a ser eliminadas se justifica quando nos deparamos com as propostas de operação urbana para "normalizar" o centro da cidade, que englobavam o "Progama de Rescate", concebido no começo dos anos 2000, viabilizado a partir da aliança entre o prefeito Manuel Lopez Obrador e o empresário Carlo Slim Helú, diretor executivo do Grupo Carso Sa. e presidente do conselho administrativo da TELMEX.

O programa surge como uma das diversas estratégias que tinham como objetivo transformar a Cidade do México na "ciudad de la esperanza" e continua em atividade ainda hoje, atuando concomitantemente a diversas políticas públicas de "revitalização" do centro. Entre outras propostas para a renovação urbana, o programa visava à eliminação de mais de 30 mil vendedores ambulantes que circulavam pelas ruas centrais da capital mexicana no início do século (WALKER, 2008).

O Programa de Rescate é, portanto, uma expressão do reinvestimento financeiro na área central da cidade que busca impulsionar uma transformação na população residente da região e incentivar a valorização simbólica do patrimônio que "encarna a identidade da cidade" (MELÉ. In: BIDOU-ZACHARIASEN, 2006, p. 200). Essas tentativas podem ser compreendidas como parte de um processo de gentrificação que não se resume a uma lógica interna de reestruturação do espaço urbano; trata-se de uma lógica muitas vezes extranacional que pode ser percebida na integração da cidade a processos de globalização econômica e cultural.

Vale notar que é comum aos processos de gentrificação o interesse em atrair para as regiões centrais um determinado grupo social, comumente formado por profissionais ligados à indústria cultural, dentre eles arquitetos, designers, artistas, entre outros. Por essa razão é interessante pensar na produção de Alÿs em relação a esse processo do qual ele, mesmo que indiretamente, faz parte.

Ainda que o interesse em atrair artistas para o centro esteja vinculado à tentativa de revalorização econômica e cultural da área, é possível pensar em práticas artísticas que permitam refletir criticamente sobre a situação. No caso de Alÿs, o esforço sistemático em registrar a realidade urbana não consiste em um posicionamento favorável ou contrário ao processo de gentrificação. A produção de Alÿs não se insere na lógica desse processo, de forma que não pode ser incorporada por ele.

Com suas fotografias, o artista não fala contra o processo de gentrificação, mas permite tornar visível a presença viva daquelas pessoas, que passam a fazer parte da visão, gerando um incômodo com os efeitos da gentrificação - aquelas pessoas tendem a ser eliminadas. Não se trata de uma estetização da miséria que apenas mostra o que já está dado, mas da invenção de um outro olhar que permite a criação de diferenças nas relações com os seres e as coisas. Alÿs não exprime um ponto de vista sobre as coisas e os seres, pois são as coisas e os seres que existem como pontos de vista que não cabem em traçados urbanos ou críticas reativas. São desvios, não denúncia. 


\section{Bibliografia}

ALŸS, Francis; DISERENS, Corinne. "La corte dos milagros.” In: Diez cuadras alrededor del estudio / Walking Distance From the Studio. Cidade do México: Antiguo Colegio de San Ildefonso, 2006.

ALŸS, Francis; FERGUSON, Russell. "Russell Ferguson in conversation with Francis Alÿs". In: MEDINA, Cuauthémoc; FERGUSON, Russell; FISHER, Jean (orgs.). Francis Alÿs. Inglaterra: Phaidon, 2007.

ALŸS, Francis; MEDINA, Cuauthémoc. Diez cuadras alrededor del estudio / Walking Distance From the Studio. Cidade do México: Antiguo Colegio de San Ildefonso, 2006. ALŸS, Francis; MEDINA, Cuauthémoc. "Entries". In: GODFREY, Mark. Francis Alÿs: A story of Deception. Inglaterra, Tate, 2010, pp. 44-169.

CAVALLETTI, Andrea. Mitología de la seguridad: La ciudad biolpolítica. Buenos Aires: Adriana Hidalgo editora, 2010.

DEBROISE, Olivier. "Puertos de entrada: el arte mexicano se globaliza 1987-1992". In: MEDINA, Cuauthémoc; DEBROISE, Olivier (Orgs.). La era de las discrepancias arte e cultura visual em México / The Age of Discrepances: Art and Visual Culture in Mexico 1968-1997. Cidade do México, México: UNAM, 2006.

ESPINOSA, Salvador García. “Centros históricos, procesos urbanos y planeación urbana en Mexico”. Quivera, Cidade do México, vol. 10, pp. 77-87, jul-dez, 2008. Disponível em: <http://www.redalyc.org/pdf/401/40113196006.pdf >. Acesso em: 15 ago. 2017.

ESPINOSA, Salvador García. "Centros históricos, ¿Herencia del pasado o construcción del presente? Agentes detonadores de un nuevo esquema de ciudad". Scripta Nova, Barcelona, vol. IX, ago. 2005. Disponível em: $<$ http://www.ub.edu/geocrit/sn/sn-194- 39.htm>. Acesso em: 06 fev. 2018. FOUCAULT, Michel. Entrevistas. São Paulo: Graal, 2006. FOUCAULT, Michel. Microfísica do poder. Rio de Janeiro: Graal, 2009.

KARNES, Andrea (org.). México Inside Out: Themes in Art Since 1990. EUA: Modern Art Museum of Fort Worth, 2013.

MANTECÓN, Álvaro Vázquez. "Los Grupos: una reconsideración”. In: MEDINA, Cuauthémoc; DEBROISE, Olivier. La era de las discrepancias arte e cultura visual em México / The Age of Discrepances: Art and Visual Culture in Mexico 1968-1997. Cidade do México, México: UNAM, 2006.

MATZKIN, Karin Ianina. Cidades latino-americanas: convergência ou diversidade no processo de produção contemporânea do espaço. Tese de doutoramento, FAUUSP, 2006.

MEDINA, Cuauthémoc; DEBROISE, Olivier. La era de las discrepancias: arte e cultura visual em México / The Age of Discrepances: Art and Visual Culture in Mexico 1968-1997. Cidade do México, México: UNAM, 2006.

MELÉ, Patrice. "(Re)investir nos espaços centrais das cidade mexicanas". In: BIDOU- ZACHARIASEN, Catherine (Coord.). De volta à cidade. São Paulo: Annablume, 2006. pp. 197 - 228.

MONSIVÁIS, Carlos, The historic center of Mexico City. Espanha: Turner, 2006. ORTEGA, Gonzalo. Arte público. Cuatro décadas de transformacion de la Ciudad de México, 2012. Disponível em: http://cral.in2p3.fr/artelogie/spip.php?article90. Acesso 
em: 10 fev. 2018.

ROLNIK, Suely. Geopolítica da Cafetinagem. 2006, disponível em http://www.pucsp.br/nucleodesubjetividade/Textos/SUELY/Geopolitica.pdf . Acesso em: 11 fev. 2018.

SÁNCHEZ, Enrique Cervantes. "El desarrollo de la Ciudad de México". Omnia, UNAM, s/d. Disponível em:

http://www.posgrado.unam.mx/publicaciones/ant_omnia/11/03.pdf. Acesso em: 15 fev. 2018.

TOURNON, Annabela. “L'art conceptuel sous influence: les Grupos (Mexique, 1970)". In: Les Cahiers du Musée national d'art moderne. Éditons du Centre Pompidou: Paris, 2012/2013.

WALKER, David. Gentrification Moves To The Global South: An Analysis of the Programa De Rescate, a Neoliberal Urban Policy in México City's Centro Histórico. Tese de doutoramento, Universidade de Kentucky, 2008. 


\section{Bibliografia complementar}

ALŸS, Francis. Walks/Passeos. México: Museo de Arte Moderno, 1997. GARCIA DOS SANTOS, Laymert. "Becoming Other to Be Oneself: Francis

Alÿs Inside the Borderline". In: GODFREY, Mark. Francis Alÿs: A story of Deception. Inglaterra, Tate, 2010, 188-190

KWON, Miwon. Dogs and the City. In: GODFREY, Mark. Francis Alÿs: A story of Deception. Inglaterra, Tate, 2010, pp. 181-182.

KWON, Miwon. "Um lugar após o outro: anotações sobre site-specific". Arte \& Ensaios. Rio de Janeiro, ano XV, No. 17, 2008. Disponível em: http://www.eba.ufrj.br/ppgav/lib/exe/fetch.php?media=revista:e17:miow.pdf. Acessado em: 08 jan. 2018. Trad. Jorge Barreto.

ROLNIK, Suely. "Subjetividade em obra: Lygia Clark artista contemporânea". In. LINS, Daniel; GADELHA, Sylvio (orgs.). Nietzsche e Deleuze: o que pode o corpo? Rio de Janeiro: Relume Dumará, 2002.

SENNETT, Richard. Carne e Pedra: o corpo e a cidade na civilização ocidental. Rio de Janeiro: Record, 2003. 